\title{
A PRELIMINARY STUDY OF FOREST TREE SUCCESSION AFTER CLEARCUT OF MATURE HEMLOCK STANDS IN SOUTHWEST NOVA SCOTIA ${ }^{1}$
}

\author{
By JOHN C. TAYLOR ${ }^{2}$
}

John C. Taylor was born January 17, 1936 at Chelmsford, England. High School education at Cheltenham Grammar School, England, and Wolfville High School, Nova Scotia. Graduated from Acadia University in 1955 with a B.Sc. with Honors in Biology, from Queens University with a M.Sc. in Mathematics in 1957, and at present studying for a Ph.D. at Toronto University.

\section{$A B S T R A C T$}

The examination of twelve different-aged, naturally regenerated cuts, the result of clearcut of mature hemlock stands, showed that the ecological composition was much the same in eight of the areas. All the tree species in the observed succession were alike in their ecological behavior. Projection of the data from the observed succession indicated that as the stand became increasingly mature the proportion of commercial trees in the association increased. No significant difference occurred between the mean number of trees per plot for commercial and non-commercial species either (i) before and during, or (ii) after the cut. On the basis of this preliminary survey it appears that natural regeneration in the areas studied will produce a forest of commercial value.

\section{INTRODUCTION}

A knowledge of the secondary succession which follows a disturbance of the climax forest by fire or cutting is useful to foresters who wish to assess the value of the natural regeneration found on old burns and cuts. In Nova Scotia few analyses of the ecology of such areas have been published. Candy (1) did some of his work in the province, and Martin (3) investigated the succession following fire in the southern counties.

The present paper is based upon the results of a preliminary survey of a clearcut area, which was designed to lead to more intensive investigations of secondary succession following cuts in selected parts of the province. In addition to testing the effectiveness of the methods employed, it was hoped to determine whether natural regeneration following cutting would result in a commercially valuable stand. In this connection the effect of the clearcut on the survival of established tree seedlings of both the "commercial" and "non-commercial" groups, and the reseeding of these following the cut, received particular attention.

The Tobeatic Game Sanctuary, in the southwestern part of Nova Scotia, is one of the few remaining places where extensive near-virgin stands of hemlock exist in the province. (Drinkwater (2) and Smith (4).) Since about

${ }_{1}^{1}$ Accepted for publication July 7, 1958.

- Perry Biological Laboratories, Acadia University, Wolfrille, N.S. 
1930 , these stands have been gradually reduced by clearcutting. The remaining forest is still harvested by the Mersey Paper Co. Ltd. for the manufacture of pulp and lumber. As a result of these cuts, areas have been cleared and left to reforest themselves. A survey of these cuts furnished the information from which the following analysis of the secondary succession was developed.

\section{METHODS}

The survey was carried out in August, 1954. Twenty-six different stages in the succession would have been available for examination if yearly cuts had been made since 1930. Since this was not the case, and since time was restricted, it was decided to examine 15 milacre plots on each of the areas cut in 1930,1931,1934,1936-38,1940,1942,1944,1946,1948,1950, 1952 and 1954. The total number of plots examined was 180 . The plots were distributed in a random way in each cut. In each plot the age, height or $\mathrm{DBH}$, and species of each tree were noted. The areas studied were chosen in the laboratory with the aid of a forest cover map of the Mersey Paper Company Ltd. A more detailed account of the method of sampling may be found in Taylor (5).

In order to determine the homogeneity of the twelve ages of cut, the mean number of trees per plot per species that germinated before or during the cut was computed for each of the cuts. The results were tabulated in a two-way classification table for species and cut. Each row of figures showed the values of this statistic for one species in the twelve cuts. The average for each row was computed, and each column of figures compared with the row average column by means of chi-square.

Three statistics were plotted against time, and proportion histograms drawn of some stages in the succession. The statistics were: first, the mean number of trees per group of species, or species, per plot; second, the rate of change of the first statistic; and third, the mean number of seedlings of a given group of species, or of a given species, per plot, divided by the mean number of trees higher than 11" per plot. Given the year in which the cut was made, it was possible to plot the values of the statistic against time elapsed since the cut was finished. The curves in Figure 2 were drawn in by eye with the aid of a French Curve through the points plotted for each statistic. Three proportion histograms were drawn from observed data. They show the succession zero, five and twenty years after the cut. In each case the proportions were computed by considering all cuts as old or older than the stage of the succession being considered. The data in these cuts were then sorted to give the information that would have been obtained had the cut been examined at the given stage. For example, when the proportion for the twenty year stage was to be obtained, the 1934, 1931 and 1930 cuts were considered. In the 1930 cuts all trees less than 5 years old were not considered. Two histograms were drawn for the seventy-year and two-hundred-year stages. The figures used in the graphs were obtained by considering the tree in each of the 180 plots which would in all probability dominate the plot at that stage of the succession. It should be pointed out that only the species represented on the histogram were considered. The others were arbitrarily rejected as being of little importance at these stages in the succession. 
The tree species found in this survey were divided into two groups: Tree species of commercial value, and those of no commercial value. The groupings are given in the following table:

TABLE I

Nomenclature of the Tree Species and Their Division into Commercial and Non-COMmercial Groups

\begin{tabular}{|c|}
\hline Commercial Species \\
\hline Scientific Name \\
\hline 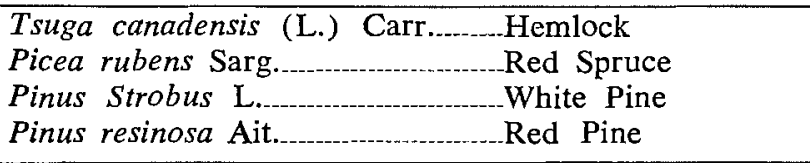 \\
\hline Non-commercial Species \\
\hline Scientific Name Common Name \\
\hline 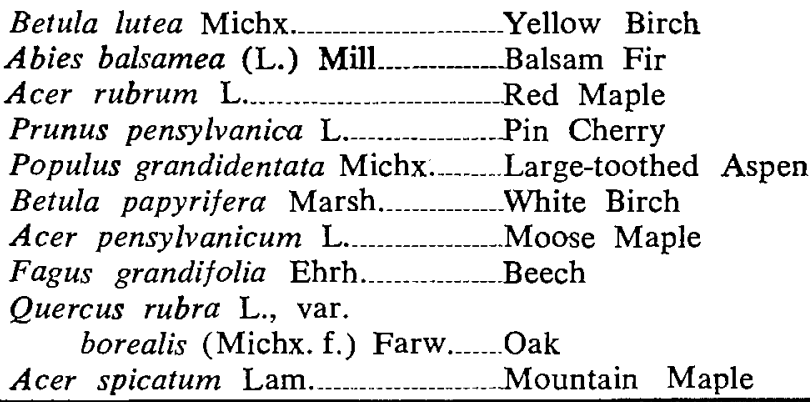 \\
\hline
\end{tabular}

The mean number of trees germinated per plot per group was calculated for each cut (i) before and during, and (ii) after the cut, Table II. The hypothesis that the means of the commercial and non-commercial rows were the same was tested. This was done for row means before and during the cut, and then for the means after the cut.

The frequency of various lengths of confidence intervals for the mean number of trees per plot was tabulated to give some idea of the usefulness of the collected data. ${ }^{3}$

RESUlts AND Discussions

The tests for homogeneity showed that two-thirds of the cuts examined were reasonably similar. Taylor (5). It is then quite probable that the ecological composition of a newly clearcut area in the Tobeatic Game Sanctuary is similar to that shown in Figure 1.

${ }^{a}$ A confidence interval is an interval about the sample mean which ean be extended to include the population mean with a given probability. 
MARCH, 1959

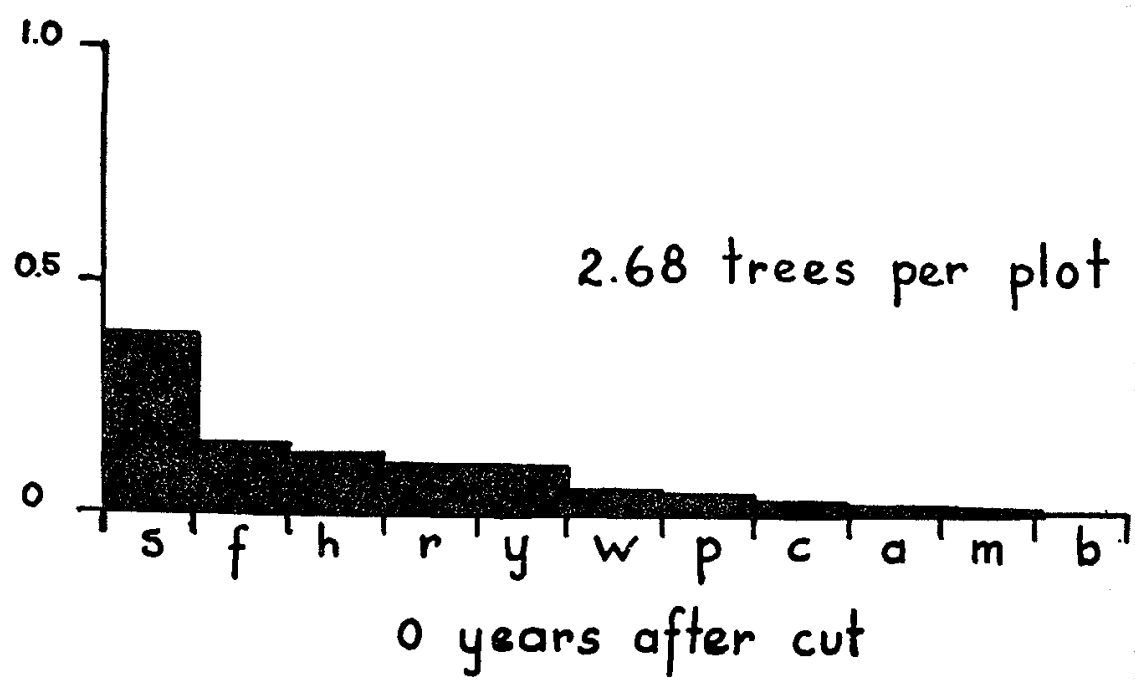

FIGURE 1

Proportion histogram for the succession zero years after the completion of the cut. See Figure 2 for key.

This graph is the proportion histogram of the row average column used in the homogeneity test. The number of trees per plot is fairly high with more than half of them belonging to the commercial group. Red spruce is the most common tree, and with fir, hemlock, red maple and yellow birch, makes up the bulk of the trees that are established before or during the year the cut was made. The other cuts were peculiar because of large numbers of one or two species. Red maple, yellow birch, and large-toothed aspen were the peculiar species in the 1952, 1950, and 1948 cuts respectively. The 1936-38 cut differed from the others because of an unusually large number of white pine trees and quite a few red spruce trees.

When cutting had been completed, the slow process of rebuilding the forest began, with the situation that is outlined above. The trends which seem to occur in the next twenty years can best be explained with reference to Figures 2 and 3. Curves, similar to those in Figure 2, were drawn for each species of tree, but are not included because they are very similar to the ones shown. The basic trend for all species and groups of species seemed to be the same. In the first ten or twelve years of the succession there was a rapid increase in the number of trees present on a plot. The proportion of seedlings to trees, which was high at first, dropped sharply in a year or two, and then stayed low throughout the rest of the first twenty years. The non-commercial species would appear to increase in number faster than the more valuable 


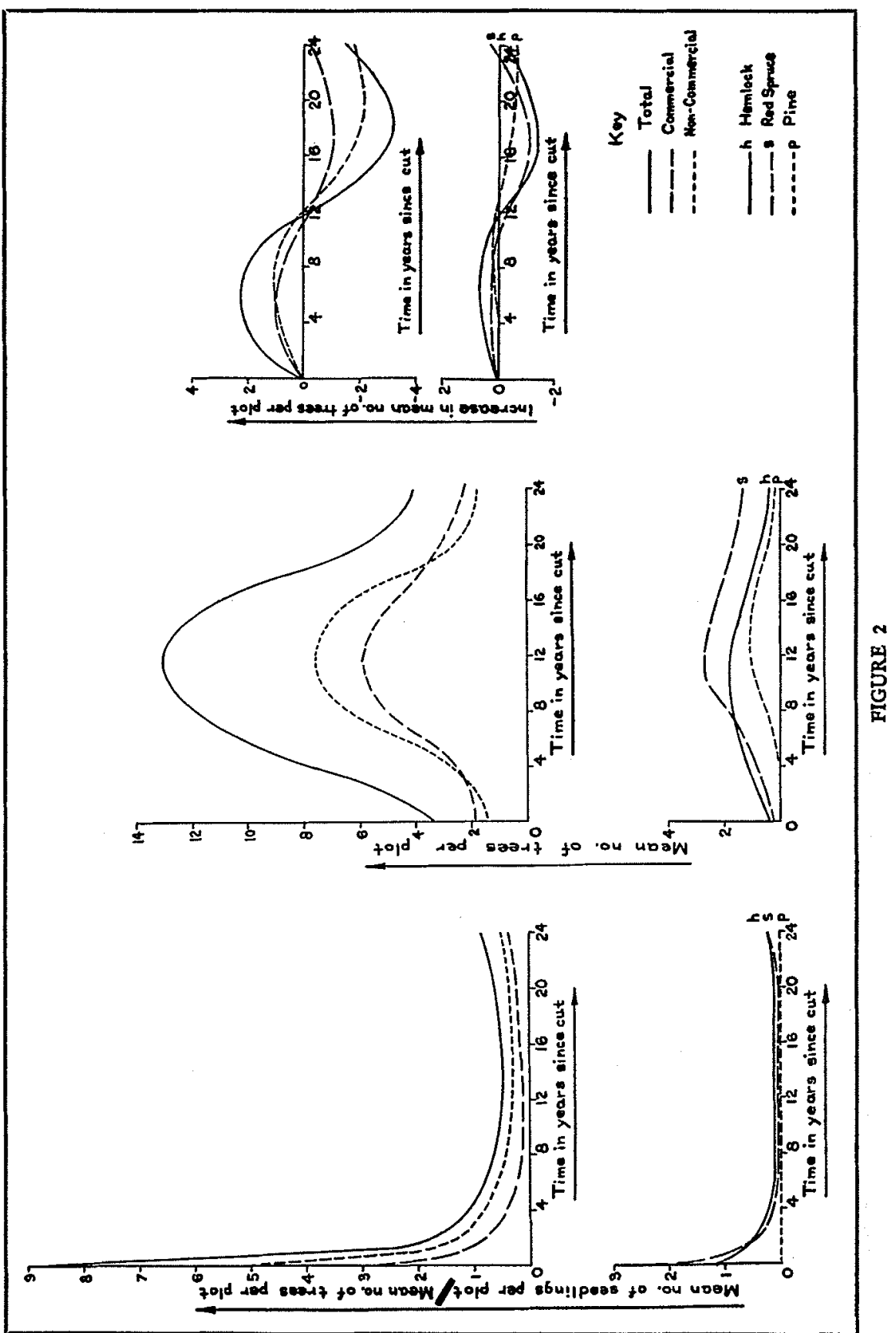




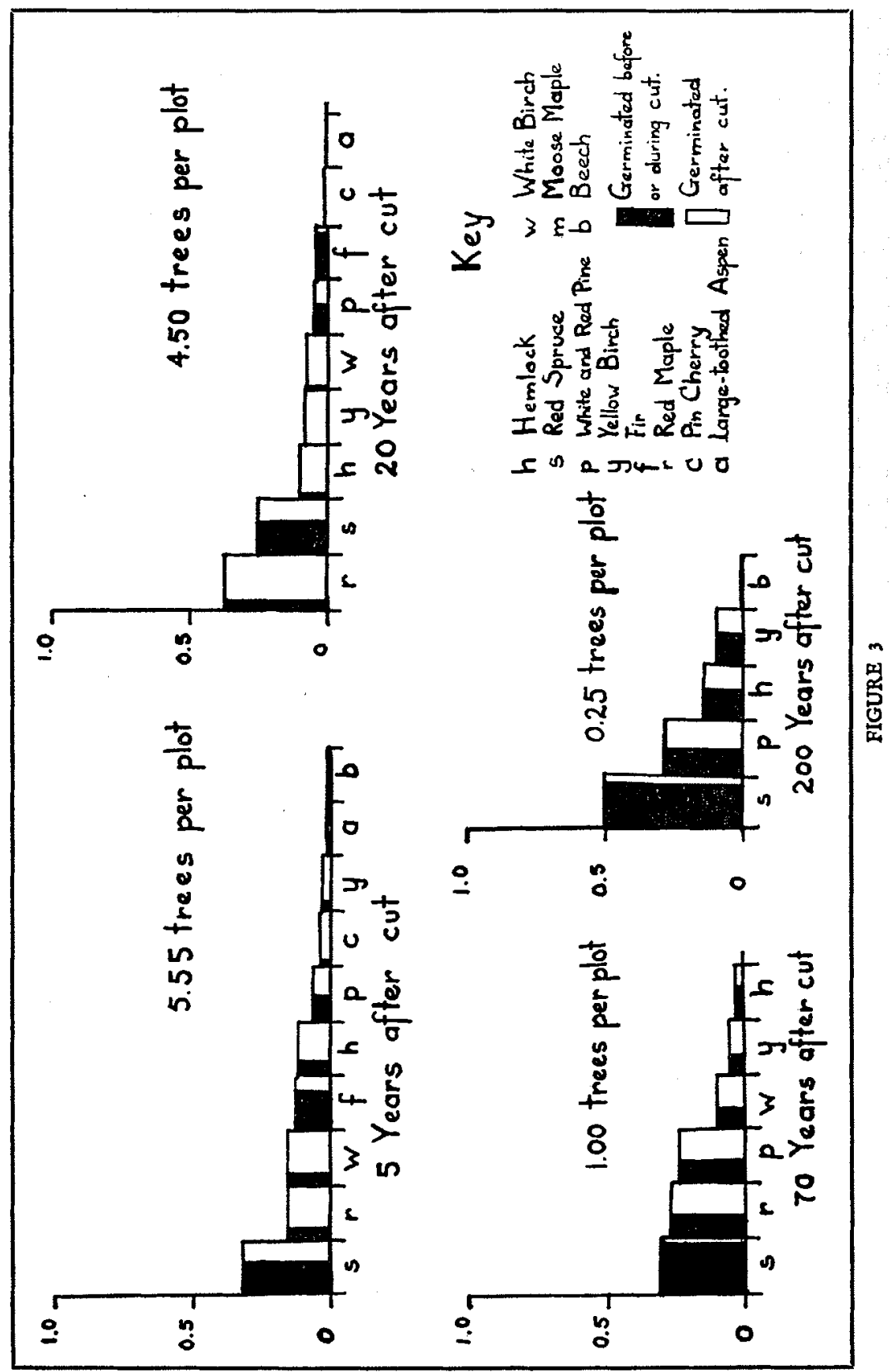


trees. In five years the number of trees per plot more than doubled, and the proportionate balance between the various species was much the same as at the start. As far as the graphs of the mean number of trees per plot and the increase in the mean number of trees per plot are concerned, the second twelve years are the reverse of the first period. The histogram for twenty years after the cut shows that the number of trees per plot was even smaller than at the first of the succession. Red maple had become commoner than red spruce and the proportionate balance was quite different from that of the earlier stages. This tendency may have been overemphasized as all data for this stage came from the three oldest cuts. These cuts had more red maple present than the others and seemed different in appearance for this reason. This brief outline of the observed succession would seem to indicate that the behavior of all tree species was on the whole quite similar. The graphs of the seventy-year and two-hundred-year stages are at best only estimates based on observed growth rates for the various species. The figures given for the number of trees per plot are to some extent arbitrary. Red spruce and white pine are shown in both cases to be the main trees present, and the proportion of commercial trees becomes larger as the succession proceeds. This is to some extent due to the fact that it was assumed that the following species (fir, pin cherry, large-toothed aspen, moose maple, and mountain maple in 70 years; and red maple and white birch in 200 years) would die out as the forest became older.

TABLE

Mean Number of Trees per Plot Germinated (i) Before and During SPECies, and the Values of $\mathrm{t}$ OB

\begin{tabular}{llccccc}
\hline & 1954 & 1952 & 1950 & 1948 & 1946 \\
\hline $\begin{array}{l}\text { Mean no. of } \\
\text { trees germinated } \\
\text { before and } \\
\text { during cut }\end{array}$ & Commercial & 0.80 & 3.07 & 1.26 & 1.87 & 0.27 \\
$\begin{array}{l}\text { Mean no. of } \\
\text { trees surviving } \\
\text { from those }\end{array}$ & Commercial & - & - & 0.73 & 0.73 & 0.34 \\
$\begin{array}{l}\text { germinated } \\
\text { after cut }\end{array}$ & Non-Commercial & - & 1.80 & 4.06 & 5.13 & 1.33 \\
\hline
\end{tabular}

t $\alpha=2.07 \quad \alpha=0.05$

TABLE

Distribution of the Lengths of Confibence Intervals for the Mean

\begin{tabular}{lrrrrrr}
\hline Length of interval & $0-1$ & $1-2$ & $2-3$ & $3-4$ & $4-5$ & $5-6$ \\
\hline Number of intervals & 31 & 27 & 11 & 8 & 7 & 1 \\
Cumulative number of intervals & 31 & 58 & 69 & 77 & 84 & 85 \\
\hline
\end{tabular}


The results of testing the hypotheses are shown in Table 2. In both cases, before and during the cut and after the cut, the hypothesis that the means were equal was accepted. This means that as far as the results obtained in this survey are concerned, there is no significant difference between the number of commercial trees and non-commercial trees that were established either before and during the cut or after the cut. The level of significance was 05 . An examination of Table 3 indicates that the lengths of confidence intervals were in quite a few cases rather great. ${ }^{4}$ Since one plot is $1 / 1,000$ of an acre, the confidence intervals for the mean number of trees per acre would in many cases be too great to be of much use. This means that the size of sample used (15 milacre plots) was in all probability too small. For this reason the results in Table II may not represent a good approximation of the actual situation in the succession.

On the basis of this preliminary study it would seem that natural regeneration in the Tobeatic Game Sanctuary will produce forest of some commercial value. The early stages of the succession tend to have more non-

-If a confidence interval for the mean number of trees per plot is to be of value, it should include the population mean a high proportion of the time, say 19/20, and be short. For example if the population mean is between 1 and $10,95 \%$ of the time, this interval is of less use than one which gives the population mean between 5 and $7,95 \%$ of the time. The length beyond which a confidence interval is not useful is arbitrary.

\section{II}

and (ii) After the Cut for Commercial and Non-commercial Tree TAINed When Testing Hypotheses

\begin{tabular}{rrrrrrrrrr}
\hline 1944 & 1942 & 1940 & $1936-38$ & 1934 & 1931 & 1930 & $\bar{x}$ & $\mathrm{~s}$ & $\mathbf{t}$ \\
\hline 3.00 & 1.21 & 0.54 & 3.27 & 0.87 & 0.20 & 1.54 & 1.49 & 1.19 & \\
1.94 & 1.67 & 1.06 & 0.47 & 1.06 & 0.34 & 0.07 & 1.18 & 0.71 & \\
& & & & & & & & & \\
6.73 & 5.07 & 3.33 & 1.80 & 1.86 & 0.86 & 2.13 & 1.97 & 2.11 & \\
6.79 & 7.00 & 8.48 & 1.33 & 3.93 & 2.21 & 0.67 & 3.56 & 2.78 & \\
\hline
\end{tabular}

III

Number of Trees Per Plot Per Species Per Time Elapsed Since Cut

\begin{tabular}{rrrrrrrrrrr}
\hline $6-7$ & $7-8$ & $8-9$ & $9-10$ & $10-11$ & $11-12$ & $12-13$ & $13-14$ & $14-15$ & $15-16$ & $25-26$ \\
\hline 1 & 3 & 2 & 1 & - & 1 & 1 & - & 1 & 1 & 1 \\
86 & 89 & 91 & 92 & 92 & 93 & 94 & 94 & 95 & 96 & 97 \\
\hline
\end{tabular}


commercial trees present than commercial ones. The non-commercial species will die out gradually and the final result would appear to be a forest dominated by commercially valuable trees. It might be pointed out that at the stage in the succession when the trees first become of immediate commercial value there is a considerable number of non-commercial trees present in the stand.

\section{ACKNOWLEDGEMENTS}

The author would like to express his appreciation of the financial assistance given by the Nova Scotia Research Foundation, the encouragement and advice of Dr. E. C. Smith, Department of Biology, Acadia University, and the statistical advice of Dr. K. D. C. Haley, Department of Mathematics, Acadia University. The author is also indebted to the Mersey Paper Co. Ltd. for permission to examine their lands and to Mr. R. S. Johnson, Chief Forester, for his aid and advice.

\section{REFERENCES}

1. CANDY, R. H. 1951. Reproduction on cut-over and burned-over land in Canada. Canada, Dept. of Res. and Dev., For. Res. Div., Silv. Res. Note No. 92.

2. DRINKWATER, M. H. 1952. A study of development in a virgin stand, Queens County, Nova Scotia. Canada, Dept. of Res. and Dev., For. Res. Div., Silv. Leaflet No. 72.

3. MARTIN, J. L. 1954. The vegetational characteristics of certain forest burn communities on the southern upland of Nova Scotia with observations on secondary succession. M.Sc. thesis, Dalhousie University.

4. SMITH, E. C. 1947-1949. Unpublished Notes.

5. TAYLOR, J. C. 1955. A Study of the succession after cut on old-2ge hemlock stands in the Tobeatic area. Honours thesis, Acadia University. 